\title{
COMPONENTES DEL DERECHO A LA PRIVACIDAD
}

\author{
COMPONENTS OF THE RIGHT TO PRIVACY
}

FAusto KuBli-García ${ }^{1}$

Resumen: A pesar de las extensas fuentes documentales que existen en materia de derecho a la privacidad, en este trabajo pretendemos hacer algunas aproximaciones metodológicas al contenido y alcance de esta rama compuesta del Derecho. En la propuesta sostenemos que se deben tomar en cuenta tres dimensiones para su entendimiento: la mínima injerencia del poder público tanto en la dinámica como en las relaciones de las personas en la órbita privada; el marco jurídico sobre protección de los datos personales; y la garantía y respeto al libre desarrollo de la personalidad. En esta trilogía podríamos incorporar todas las instituciones que derivan del orden jurídico que de alguna manera regulan o atienden a la privacidad de las personas, enmarcando o proponiendo un concepto objetivo de derecho a la privacidad al que podríamos agregar una idea subjetiva de derecho a la privacidad. También destacamos la importancia que reviste definir el contexto en el que las relaciones transgreden la privacidad, las cuales pueden ser entre el poder público y los particulares o entre particulares.

Palabras Clave: Derecho a la privacidad, derechos fundamentales, libertades fundamentales, libre desarrollo de la personalidad, protección de datos personales.

Abstract: Despite the extensive documentary sources that exist in terms of right of privacy, in this work we intend to make some methodological approaches to the content and scope of this brnach composed of Law. In the proposal we argue that three dimensions must be taken into account for its understanding: the minimum interference of public power in both in the dynamics and relationships of people in the private orbit; the legal framework on protection of personal data; and the guarantee and respect for the free development of personality. In this trilogy we could incorporate all the institutions that derive from the legal order that in some way regulate or address the privacy of people, framing or proposing an objective

${ }^{1}$ Profesor de carrera de la Facultad de Derecho de la UNAM de materias de la Licenciatura y del Posgrado. Comentarios al correo electrónico <faustok@unam.mx> y al Twitter<@Faustokubli> 
concept of the right to privacy to which we could add a subjective idea of the right to privacy. We also highlight the importance of defining the context in which relationships transgress privacy, which may be between public power and individuals or between individuals.

KEYWORDs: Right to Privacy, Fundamental Rights, Fundamental Freedoms, Free Development of Personality, Personal Data Protection.

SUMARIO: I. Introducción; II. Mínima injerencia justificada y legal; III. La protección de los datos personales; IV. Libre desarrollo de la personalidad; V. Consideraciones finales; VI. Fuentes.

\section{INTRODUCCIÓN}

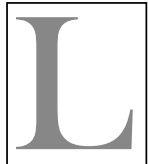

a palabra privacidad (lat. privātus) hace referencia a algo que se opone a lo público, que se encuentra fuera del escrutinio, asimismo, algo que pertenece o es usado solamente por alguna persona o grupo; de igual manera, algo que ha sido marginado o se ha quitado la pertenencia. Como otros conceptos relacionados con los valores humanos, la privacidad tiene en su delimitación aspectos de vaguedad, ${ }^{2}$ por ello nos dimos a la tarea de llevar a cabo este ejercicio de buscar una serie de aproximaciones para comprenderla, al menos, de manera jurídica. En este sentido, para allegarnos a este objetivo, lo inmediato es reconocer que la privacidad es un principio. Como principio jurídico, con naturaleza abstracta, pretende, por un lado, ser el punto de partida para crear una instrumentación posterior y, por otro lado, ser fundamento, causa, de las normas sobre privacidad.

\footnotetext{
${ }^{2}$ Bloustein Edward, Privacy as an Aspect of Human Dignity, en New York University Law Review, NYU, Volumen 39, 1964, página 1001. El profesor Bloustein considera que "Las palabras que se usan para identificar y describir los valores básicos humanos son necesariamente vagos y las peores en definir. Estan compuestas por profundos deseos y esperanzas que por un lado, hay aspectos empíricos y sicológicos humanos difíciles de retener, y por otro lado, nuestros objetivos sociales se adecuan más a lo que pronuncian profetas y poetas que a lo que digan los profesores. Tenemos la fortuna, entonces, de que algunos de nuestros jueces tienen visión de profeta y lengua de poetas.” The words we use to identify and describe basic human values are necessarily vague and ill-defined. Compounded of profound human hopes and longings on the one side and elusive aspects of human psychology and experience on the other, our social goals are more fit to be pronounced by prophets and poets than by professors. We are fortunate, then, that some of our judges enjoy a touch of the prophet's vision and the poet's tongue.
} 
En el caso del derecho a la privacidad, como un concepto jurídico, la connotación se orienta hacia la esfera personal, al conjunto de normas que abordan, gestionan o regulan este estadio propio de las personas. De esta manera, una primera aproximación la proponemos al definir al derecho objetivo a la privacidad, como todas las disposiciones del orden jurídico nacional, de fuente interna o internacional, constitucionales, legales, reglamentarias o jurisprudenciales que atañen, inciden o se refieren a la privacidad de las personas en tres dimensiones, esto es, los derechos relacionados con la injerencia mínima del poder público en las relaciones particulares, la protección de los datos personales y el libre desarrollo de la personalidad. A partir de esta definición se puede elaborar un entramado de todas las normas relacionadas, pero que también se incorporan desde el punto de vista de las relaciones intersubjetivas, sean público-privadas o meramente privadas. De la misma manera, se incorporan las asociaciones con otros derechos enfrente del poder público como el principio de legalidad, la libertad de expresión, el derecho a la intimidad. $^{3}$

En el desarrollo de esta breve investigación procede hacer una distinción conceptual entre los términos de "intimidad”, "privacidad”. Si bien existe un hilo conductor entre estas voces, en este texto se propone la utilización de conceptos jurídicos de fuente judicial. Esto es, son las resoluciones judiciales, las sentencias de las cortes las que dan luz al contenido y alcance de estos vocablos. Sin embargo, podríamos establecer una gradualidad en tanto la "intimidad" está asociada con la "privacidad" de una manera más profunda, por ejemplo, existe un proyecto de Ley de Protección a la Intimidad ${ }^{4}$ que castiga la difusión de pornografía no autorizada. De esta manera, se coloca al concepto de "intimidad" como características, conductas mucho más internas y privadas que las demás.

\footnotetext{
${ }^{3}$ En principio, consideramos a la intimidad como una parte de la privacidad, en el entendido de que lo íntimo responde a algo o alguien cercanamente a la persona.

${ }^{4}$ Esta ley pretende criminalizar la exposición no autorizada de imágenes y videos con contenido sexual. Intimate Privacy Protection Act Recuperado el 13 de septiembre
} 
Añadimos a esta delimitación, el marco teórico de referencia que parte de la propuesta de Ferrajoli en el ámbito de los derechos fundamentales. ${ }^{5} \mathrm{Al}$ respecto, el enfoque sistémico de funcionamiento de los derechos fundamentales entorno a la privacidad, la democracia como un elemento sustantivo de este tipo de derechos, la supranacionalidad, la definición normativa y sus garantías procesales. Por consecuencia, una aproximación secundaria la podríamos enmarcar como el derecho subjetivo a la privacidad, vista a la persona como titular de derechos, es decir, el conjunto de normas jurídicas que reconocen y brindan alguna prerrogativa, facultad, atribución a las personas de resguardar elementos de su vida, su entorno inmediato, basadas en la libertad y en los límites autoimpuestos. En este tenor, la transgresión de los límites autoinferidos por las personas a su medio entran en el campo de las responsabilidades, tal y como lo abordamos en este trabajo.

Es importante resaltar que el derecho a la privacidad está constantemente en desarrollo, sobre todo en el escenario actual de hipercomunicación, no es un sistema normativo acabado, incluso en sistemas notablemente evolucionados en este tema, como el británico o el alemán. ${ }^{6}$ Por ejemplo, las tecnologías de la información han hecho repensar tanto a los teóricos como a los practicantes los modelos jurídicos que regulan la privacidad. Se añade también al fenómeno el contenido económico que hoy en día tiene la información, entre ella, la información relacionada con la privacidad de las personas, que es el insumo principal para generar publicidad focalizada. También este escenario ha impactado en otras dimensiones de la privacidad, como la relacionada con las distintas responsabilidades que pudieran generarse en redes sociales y medios de comunicación masiva.

Figuran en esta investigación una serie de elementos teóricos y prácticos que pretenden consolidar la argumentación sobre la naturaleza y aproximación metodológica que se desarrolla en torno al derecho a la privacidad. En varias partes, tomamos en cuenta decisiones judiciales que pretenden

de 2018, de https://speier.house.gov/sites/speier.house.gov/themes/jackiespeier/images/IPPA_Final.pdf

${ }^{5}$ Ferrajoli, Luigi, Derechos y Garantías. La ley del mas débil, Editorial Trotta, 2002, pp. 15-35.

${ }^{6}$ Vid. O Callaghan Patrick, Refining Privicy in Tort Law, Reino Unido, Ed. Springer, 2013, pag. 184 . 
conceptualizar este derecho o partes de este derecho. Nos allegamos a la jurisprudencia angloamericana como un apoyo indiscutible, dado que la tradición del case law es un referente por su conceptualización. En muchas ocasiones las sentencias de la Corte Suprema de los Estados Unidos, además de resolver conflictos, generan condiciones posteriores que sirven de herramientas para la instrumentación de políticas públicas. De ahí por supuesto la justificación que encontramos para tomar esas referencias.

Sin lugar a dudas, existen muchas propuestas en torno a la idea de privacidad, desde el punto de vista social, como un acercamiento antropológico, e incluso, dentro del derecho hay una variedad de formas. Hay tendencias teóricas que han reposado a la privacidad en una composición de intereses que se refieren a la reputación personal, a la tranquilidad emocional y a una especie de propiedad intangible. ${ }^{7} \mathrm{Al}$ respecto, se han ido superando varias concepciones que se tenían sobre la privacidad, entre ellas, las que la relacionaban como un nivel de propiedad personal. En esta propuesta, no hacemos una reflexión exhaustiva particular de todas las normas relacionadas con la privacidad. Nuestro objetivo es señalar una metodología que consista en identificar en tres conjuntos a las normas relacionadas con la privacidad a partir de elementos teóricos, pero también prácticos, constitucionales, legales y jurisprudenciales. Como objetivo de esta investigación, establecemos de manera elemental los componentes del derecho a la privacidad. Consideramos que las normas sobre privacidad las podemos circunscribir por su naturaleza a tres tipologías basadas en la injerencia a la esfera personal, la información personal y las decisiones personales.

${ }^{7}$ Prosser William M, Privacy, California Law Review, Volumen 48, Número 3, Agosto de 1960, pp. 383-423. 


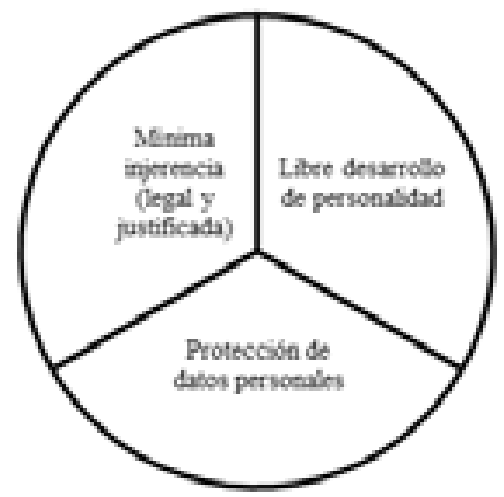

El primer tipo de normas a que nos referimos son aquellas que facultan algún tipo de injerencia sobre la vida privada, en especial sobre los bienes materiales y próximos de las personas. Sin duda, a este tipo de normas corresponde un extenso surtido de disposiciones a partir del significado de "injerencia”, cuya dimensión es altamente extensa. Sin embargo, son los primeros rasgos de los derechos humanos, basados en las libertades, los que le dan vida a esta idea de protección a la vida privada. Es la libertad individual que recorre un tipo de disposiciones jurídicas que permiten mínimamente la intromisión del poder público en la vida de las personas. En este sentido, la libertad que es el eje rector se simplifica en normas jurídicas que justificadamente atienden a la intervención mínima, expresada desde distintas ópticas.

En segundo lugar, nuestra propuesta aborda a otro conjunto de normas jurídicas relacionadas con la privacidad en términos de la titularidad y disponibilidad de la información personal. Nos referimos al marco normativo de la protección de datos personales que atiende a concebir a la información personal como un elemento indisoluble de la persona, quien es el titular de la información que circunda a su alrededor y que solamente él tiene

\footnotetext{
${ }^{8}$ Cuadro elaborado por la pasante Sofía Morín Pérez, ayudante de investigación en la Facultad de Derecho.
} 
el derecho a fijar el destino de su información. La confidencialidad de la información se refiere directa e inmediatamente a la privacidad, traducida en la proscripción de acceso no autorizados a los datos de una persona.

La tercera dimensión que proponemos como aproximación metodológica del derecho a la privacidad se refiere al conjunto de normas relacionadas con el libre desarrollo de la personalidad. Esta se traduce en la serie de decisiones que tiene cada persona para preferir determinada conducta y aunque podríamos encasillar estas normas como "injerencistas", consideramos que tienen sus propias particularidades, en principio por la referencia individualista que tiene este concepto. Esta individualidad está ceñida a la propia persona, decisiones que afectan directamente a ella y que no tienen repercusiones sobre el bien común o que afecten en su esfera de derechos a terceros. Asimismo, se trata de normas que hacen una interferencia decisional, mas de carácter ideal que material.

\section{MÍNIMA INJERENCIA JUSTIFICADA Y LEGAL}

El término que empleamos como "mínima injerencia” es la base y el sustento de las relaciones entre el poder público y los particulares. Se trata también del mecanismo orientador en términos jurídicos de la libertad en estos términos. Cabe destacar que sus orígenes son remotos y podríamos ubicarlo desde la Carta Magna de 1215, dado que se inscribe en su funcionamiento el célebre principio de legalidad que pretende otorgar certeza a las personas con respecto a la actuación del poder público. Sin lugar a dudas, el principio de legalidad se asocia a otros conceptos como la rendición de cuentas, el estado de derecho, sin embargo, en este trabajo lo abordamos desde el punto de vista del que consideramos el derecho a la privacidad.

La injerencia del poder público en la vida privada puede ser orientada por ideas paternalistas. En este sentido, el paternalismo como base de la construcción de políticas públicas se refiere a la posibilidad de entrometerse en la vida de la población, afectando su voluntad. Cabe destacar que existen distintas tipologías en la que el paternalismo puede ser concebido. Existe la idea del paternalismo rígido en la que existe una alta proclividad 
a la intervención del poder público en las relaciones de los particulares. Por otro lado, el paternalismo suave establece un límite más restringido de interferencia y solamente se hará cuando no sean actos voluntarios y conscientes. De igual manera, hay paternalismo amplio, el cual se refiere a la acción integral, esto es, a llevar a cabo acciones tendientes a la satisfacción de derechos sociales de campo de acción restrictivo. Por su parte, el paternalismo restrictivo solamente responde a la coerción del Estado.

Por otro lado, están el paternalismo fuerte y el paternalismo débil, en este sentido la debilidad significa que se podrán interferir en las personas en los medios que escogen para lograr sus fines, por su parte la fortaleza del paternalismo considera que las personas toman malas decisiones y por ello se legitima la injerencia. De igual manera, hay paternalismo puro que se refiere a la interferencia de un cierto sector de la población, mientras que en el paternalismo impuro la intervención es a un sector más amplio. Finalmente el paternalismo benefactor y el paternalismo moral, el primero se traduce en las condiciones que puede proponer el poder público para que una persona tenga óptimo desarrollo psico-social; sin embargo, el paternalismo moral hace referencia cuando una medida de esa clase tiene una carga moral al respecto. ${ }^{9}$

Proponemos la aproximación al derecho a la privacidad en tanto, en determinados y reducidos casos, está justificada y legalizada la intervención del poder público en las relaciones de los particulares, es decir, en la vida privada. De esta manera, la expresión más liberal que encontramos en la Constitución mexicana está incorporada en el artículo 16 al tiempo de establecer como norma general "Nadie podrá ser molestado en su persona, familia, domicilio, papeles o posesiones...” Al respecto, la libertad se traduce en dejar a la población tomar sus propias decisiones en tanto no transgredan la esfera de derechos de los demás y por supuesto el orden jurídico. De ahí derivan varios cuestionamientos, ¿qué tan extenso es el concepto de “propias decisiones”?, la respuesta se contesta caso por caso, de manera concreta en términos específicos.

${ }^{9}$ Dworkin, Gerald, "Paternalism”, en Edward N. Zalta (editor), The Stanford Encyclopedia of Philosophy, Ed. Metaphysics Research Lab, Stanford University, 2017. Recuperado el 14 de enero de 2019 en <https://plato.stanford.edu/archives/win2017/entries/ paternalism/>. 
Dentro de nuestra propuesta circunscribimos algunos elementos básicos para comprenderla. En primer lugar, en este apartado, estamos haciendo referencia a las relaciones entre poder público y particulares; en segundo lugar, es posible que se pueda interferir en la vida privada de las personas; en tercer lugar, subrayamos que esa interferencia debe estar ampliamente justificada; en cuarto término, la justificación de la interferencia en la vida privada debe estar incorporada en alguna disposición del orden jurídico.

El papel del derecho ante los particulares reposa en la libertad; la privacidad y todas las disposiciones que se asocian a ella están determinadas por este concepto. Discutida por miles de años, desde Aristóteles hasta Locke e incluso en la actualidad, ${ }^{10}$ la libertad se ha visto de manera positiva como la forma de autodeterminarse, sin embargo, dentro de las relaciones entre el Estado moderno democrático, basado en derechos y libertades, la óptica de este concepto es distinta. En este sentido, la libertad personal, que incluye el entorno y loa ámbitos de desarrollo de los individuos puede ser objeto de intromisión por parte de las instituciones del poder público. Esta intromisión, injerencia o intervención es dada en principio para lograr los fines propios del Estado, entre ellos el bien común. Esto es que el sacrificio de la individualidad al permitir la injerencia pública gravita de manera directa (o al menos así debiera) en el interés público, el mismo patrón y base con el que se construye el orden jurídico.

Por su parte, la injerencia del poder público en las relaciones de los particulares puede expresarse en prohibiciones, cargas, limitaciones, imposiciones. En todo caso, las intervenciones en la vida particular conllevan a que la autodeterminación esté restringida por razones justificadas. Por ejemplo, los delitos incorporados en los códigos penales justifican la actuación del poder público, de igual manera, la intromisión a través de diligencias e investigaciones en la vida particular para esclarecer y responsabilizar al que contravino lo establecido en las disposiciones penales. En

\footnotetext{
${ }^{10}$ Véanse el concepto de "Libertad" en Abbagnano, Nicola, Diccionario de Filosofia, México, Fondo de Cultura Económica, 1963, pp. 738-747.
} 
este ejemplo, la "intromisión” que significan una serie de actos de molestia están dentro de la razonabilidad de la actuación del poder público. El daño social que provoca la delincuencia es la base y fundamentación suficiente para poder transgredir de manera dirigida y legal a la libertad de las personas, es decir, en muchos casos a la privacidad. Dese este punto de vista, el cateo se convierte en una ecuación de intervención justificada; y la actuación policial es corroborada de manera judicial, dado que pretende garantizar la seguridad jurídica, la cual en el fondo reposa en la libertad.

Los impuestos son otro buen ejemplo de cómo se puede manifestar la intervención del poder público en la vida privada. La riqueza que generan las personas, la cual es producto de su esfuerzo físico y mental, es tasada en un porcentaje para cubrir el gasto público, esta intervención encuentra su justificación en la aplicación de estos recursos en beneficio de todos, que sin dudas es una idea de interés público. De esta manera, también emana la idea de rendición de cuentas inscrita en la aplicación de los recursos que las propias personas han proporcionado para que se lleven a cabo los fines tales como la salud, la seguridad, los servicios públicos, la impartición de justicia, entre otros.

En suma, cualquier disposición que faculte a la autoridad pública a llevar a cabo injerencias en la vida privada de las personas debe estar basada en lo que consideramos una justificación primaria. ${ }^{11}$ Consideramos a ésta como el conjunto de razonamientos del orden primario, en virtud de tratarse de la base, el origen de el derecho positivo. Las exposiciones de motivos en las leyes contienen estas justificaciones primarias que se componen de una serie de argumentos del porqué debe promulgarse la ley que se expide. Es importante resaltar que las justificaciones primarias normalmente obedecen a lo políticamente razonable, sin embargo el argumento en contra de una ley, esgrimiendo la erosión o pérdida de la libertad, debe considerarse en el cuerpo de las motivaciones. Ahora bien, la justificación primaria no es un trabajo acabado, estático, puede ser debatirse, aún después de incorporarse a la letra de la ley. De hecho cuando se discute en las cortes supremas la constitucionalidad o no de una norma, se replantea la

\footnotetext{
${ }^{11}$ Es necesario aclarar que consideramos como justificación secundaria la motivación de
} 
justificación primaria y su compatibilidad con el régimen constitucional.

Es importante resaltar que el derecho a la privacidad en muchos escenarios está rodeado de complejidad, cuyas respuestas no son sencillas, dado que no hay una regla general que establezca el sentido de una decisión, esto es, siguiendo a Dworkin, ${ }^{12}$ susceptible de florecer casos difíciles. Como ejemplo de la dimensión que proponemos -como una de tres partes del derecho a la privacidad- cabe mencionar el régimen jurídico de la geolocalización, que en México está establecido en el artículo 303 del Código Nacional de Procedimientos Penales, el cual facultaba a las procuradurías y fiscalías el acceso a los datos de posición de los teléfonos móviles.

En un principio, merced al artículo 303, la geolocalización podría ser solicitada por el ministerio público (local o federal) directamente a los concesionarios y permisionarios de las telecomunicaciones, lo cual fue impugnado por el entonces IFAI y la CNDH. ${ }^{13}$ En las demandas se arguyó que este modelo violaba el derecho a la privacidad en virtud de que consistía en un acto de molestia que no era validado por un juez. En el esquema liberal democrático expuesto, la intervención a la privacidad puede darse siempre y cuando sea validada, corroborada por el poder judicial, es decir, bajo controles judiciales.

Es importante destacar que antes de dictar sentencia, el artículo 303 fue reformado, ${ }^{14}$ incorporando la participación de los jueces de control en la intervención de los aparatos electrónicos susceptibles de ser localizados por el sistema de Posicionamiento Global, lo cual obedece a

la ley exigida en todo acto de autoridad, es decir el arco narrativo que se debe expresar para la operatividad legal. En suma la justificación primaria es la base y el principio de la existencia de las leyes y la justificación secundaria opera en la aplicación de la norma ya existente.

12 Dworkin, Ronald, Hard Cases, en Harvard Law Review, Vol. 88, No. 6 (Apr., 1975), pp. 1057-1109.

${ }^{13}$ Sentencia de las acciones de inconstitucionalidad 10/2014 y 11/2014 acumulada promovidas por la Comisión Nacional de los Derechos Humanos y el Instituto Federal de Acceso a la Información Pública Gubernamental ante la Suprema Corte de Justicia de la Nación. Recuperado el 14 de enero de 2019 en la siguiente cibergrafía http://www. cndh.org.mx/sites/all/doc/Acciones/Acc_Inc_2014_10_Demanda.pdf

14 Decreto publicado en el Diario Óficial de la Federación el 17 de junio de 2016. Recuperado el 14 de enero de 2019 en la siguiente cibergrafía http://www.dof.gob.mx/ nota_detalle.php? $\operatorname{codigo}=5441763 \&$ fecha $=17 / 06 / 2016$ 
parámetros proporcionales y razonables que deben guiar la transgresión de la privacidad. En sus resoluciones la Corte tuvo la disyuntiva de validar la intervención sin control judicial en casos urgentes, finalmente el artículo 303 -que estuvo vigente del 2014 a junio de 2016- fue declarado inconstitucional, entre otras cosas porque no acotaba a un determinado tipo de delitos (delincuencia organizada, delitos contra la salud, secuestros, extorsión y amenazas).

\section{LA PROTECCIÓN DE LOS DATOS PERSONALES}

La segunda esfera de disposiciones consideradas dentro del universo del derecho a la privacidad son las relacionadas con la protección de los datos personales. La asociación que existe entre determinada información concerniente a una persona es el conjunto de datos personales. Dentro de esta dimensión hay un caudal de disposiciones jurídicas que reconocen tanto la titularidad de los datos personales, como un sistema de responsabilidades. Cabe destacar que la protección de datos personales está considerada como un derecho humano fundamental, oponible erga omnes, es decir, ante cualquier institución pública y ante sujetos privados. Otro elemento que se debe señalar es el del contexto de las tecnologías de la comunicación que, en esta área, también ha impactado notablemente. El incremento en la digitalización de datos y el conocimiento generado en las tecnologías de la información han permitido que tanto instituciones públicas, como privadas accedan y recolecten información personal sobre consumidores y ciudadanos. Esto es de resaltar, dado que se ha generado un intenso mercado de datos personales en el que la información se convierte en un objeto de comercio.

La naturaleza particular e independiente de las disposiciones sobre datos personales es evidente, aunque relacionadas con los otros componentes del derecho a la privacidad, tienen su propio estatus y se enfocan a determinar el manejo de la información confidencial, cuyo significado recae en la definición legal clásica de los datos personales. ${ }^{15}$

\footnotetext{
${ }^{15}$ La definición legal más aceptada es la siguiente: “Cualquier información concer-
} 
Consideramos en este universo tres tipos de disposiciones de distintas fuentes en torno a la protección de datos personales. En principio, las normas sustantivas que le dan titularidad a las personas sobre una serie de derechos subjetivos que se asocian a sus datos personales; en segundo lugar, las disposiciones procesales-institucionales que instrumentan el manejo y gestión de datos personales; y un tercer conjunto de normas relacionadas con el régimen de responsabilidades que pudiere surgir por el rompimiento de la confidencialidad.

La relación de la protección de los datos personales con la privacidad es evidente, el lenguaje que se utiliza, básicamente se refiere a la confianza en depositar en alguien determinados datos. De hecho, "confidencial”, tiene en su raíz etimológica la expresión "con confianza” (con+fide), justo se refiere a que esa confianza se cumpla en el momento en que se entregue determinada información. Las normas de protección de datos personales en casi todas las latitudes no autorizan la disposición de la información en tanto no sea consentida por el titular y castigan el rompimiento de la confidencialidad porque se invade la privacidad.

De manera sustantiva, las normas de protección de datos personales pretenden, o tienen como objetivo, que las personas físicas tengan pleno control de su información. En este control se encuentra incorporada la voluntad, el consentimiento de la persona de querer compartir o no su información personal. De esta manera, las disposiciones que hay en torno a los datos personales encuentran un diferenciador de acuerdo a la naturaleza de las entidades que las piden y poseen, es decir, públicas y privadas. En todo caso, el titular de los datos personales tendrá los derechos inherentes y reconocidos por la Constitución mexicana en el segundo párrafo del artículo 16, los derechos ARCO:

Toda persona tiene derecho a la protección de sus datos personales, al acceso, rectificación y cancelación de los mismos, así como a manifestar su oposición, en los términos que fije la ley, la cual establecerá los supuestos de excepción a los principios que rijan el tratamiento de da-

niente a una persona física identificada o identificable.” 
tos, por razones de seguridad nacional, disposiciones de orden público, seguridad y salud públicas o para proteger los derechos de terceros.

Estos derechos ARCO (acceso, rectificación, cancelación y oposición) son la instrumentación práctica del control de los datos personales señalados. Cada una de estas prerrogativas -que tienen los titulares de los datos personales- se enmarcan en una facultad distinta con respecto a los datos personales. El derecho de acceso se ejerce por el titular y consiste en la solicitud que se lleva a cabo sobre sus datos personales, así como la fuente de la que fueron recabados, el manejo que se hace de ellos, las transferencias que se hayan hecho de ellos y el acceso al aviso de privacidad; por su parte, el derecho de rectificación se entiende como la facultad que tiene el titular de sus datos personales de solicitar la corrección de ellos cuando sean imprecisos, inexactos, inadecuados, incompletos; en otro tenor, el derecho de cancelación se traduce en la facultad que tienen las personas de solicitar la eliminación de sus datos de la base o contenedor en el que estén depositados; finalmente, el derecho de oposición se ejerce por el titular de los datos personales cuando no se está de acuerdo con el tratamiento que se les está dando, es decir, la finalidad por los que fueron recabados, la cual debiera estar en concordancia con el consentimiento de la persona.

Por otro lado, dentro de los derechos sustantivos inherentes a los datos personales se encuentran los que los categorizan en datos ordinarios y sensibles. Dependiendo el grado de intimidad, los datos personales podrán ser reconocidos y deberán sujetarse a disposiciones diferenciadas sobre acceso, gestión y tratamiento. Por datos sensibles se entienden los relacionados con la salud de las personas, su origen étnico, sus orientaciones sexuales, sus preferencias políticas, la información genética. Un elemento diferenciador de los datos sensibles, dado que la enunciación anterior no es exhaustiva, es que se refiere a cualquier información que pudiera provocar alguna conducta discriminatoria en el titular de los datos.

Adyacentes a los derechos sustantivos sobre protección de datos personales se encuentran las disposiciones procesales-institucionales. Distin- 
guimos a este tipo de normas de las otras, dado que su naturaleza se refiere al ejercicio de las disposiciones sustantivas, en el sentido de crear procedimientos, organismos, para gestionar, administrar y procurar un tratamiento apropiado de los datos personales. En este sentido, tanto en el ámbito público como en el privado, la gestión de los datos personales cobra importancia y las leyes en todo caso imponen restricciones y la creación de avisos de privacidad, que fungen como el instrumento indispensable para recolectar datos personales.

En el ámbito público se han creado sistemas de gestión de datos personales para brindar seguridad en el tratamiento de la información de las personas. En este sentido, las entidades públicas deben tener una serie de lineamientos preventivos y seguros que garanticen que los datos personales serán utilizados para los fines por los que han sido recabados y no sean compartidos en el marco de las solicitudes de acceso a la información, o bien extraídos informalmente de las bases de datos en los que están contenidos. En México el derecho aplicable a estos casos, además de las disposiciones constitucionales, se encuentran en la Ley General de Protección de Datos Personales en Posesión de Sujetos Obligados. ${ }^{16}$

Por otro lado, en el orden jurídico mexicano también se ha dado un despliegue importante de normas que protegen la privacidad de las persona ante particulares. Para tales efectos se cuenta con la Ley Federal de Protección de Datos Personales en Posesión de Particulares, ${ }^{17}$ que tiene por objeto regular el tratamiento de los datos personales con la intención de que sea controlado e informado y así salvaguardar la privacidad de las personas y el control -que la Ley llama autodeterminación- de la información personal.

A pesar de leyes y reglamentos que existen en materia de privacidad, los medios de comunicación socio-tecnológicos representan un enorme desafío. En la actualidad hay un importante contenido económico de los datos perso-

${ }^{16}$ Ley General de Protección de Datos Personales en Posesión de Sujetos Obligados, publicada en el Diario Oficial de la Federación el 26 de enero de 2017. Recuperado el 13 de septiembre de 2018, de http://www.diputados.gob.mx/LeyesBiblio/ref/lgpdppso.htm

${ }^{17}$ Ley Federal de Protección de Datos Personales en Posesión de Particulares, publicada el 5 de julio de 2010 en el Diario Oficial de la Federación. Recuperado el 13 de septiembre de 2018, de https:/www.gob.mx/cms/uploads/attachment/file/123648/Ley_Federal_de_ Protecci_n_de_Datos_Personales_en_Posesi_n_de_los.pdf 
nales, otra de las características de este nuevo paradigma de comunicación. Aunado a lo anterior, se estima que el 90 por ciento de los adolescentes son usuarios de redes sociales, ${ }^{18} \mathrm{y}$ cada vez son más sofisticadas las formas en que se invade a la privacidad, desde el teléfono móvil, la computadora y hasta los televisores pueden estar invadiendo el ámbito íntimo de las personas. ${ }^{19}$ Esta invasión normalmente está consentida por los usuarios de los medios electrónicos, pero también normalmente desconocen que están siendo escuchados, seguidos y hasta observados en sus casas.

Las circunstancias que existen en torno a la protección de datos personales son complejas, por lo mismo el sistema de responsabilidades debe tener una gran cantidad de elementos. En este sentido, se han delimitado cuatro momentos en los que se pueden producir responsabilidades en materia de protección de datos personales: recolección, procesamiento y difusión. ${ }^{20}$ En todo caso, en toda esta dimensión de la privacidad gira el consentimiento al respecto, es decir, sin consentimiento se conflagra el acto ilícito, la intromisión en la privacidad.

La recolección de datos puede es ilícita aunque no exista la divulgación de ellos. Básicamente, puede darse por vigilancia o por interrogatorio. La vigilancia puede tener muchos fines, como el control social, que tendría, en principio vocación preventiva y persecutoria de los delitos, pero también puede restringir la libertad personal; por otro lado, la vigilancia también puede dar como resultado la posibilidad de crear publicidad dirigida y precisa. Por su parte el interrogatorio, hay que tomarlo en sentido amplio, es decir, la recolección de datos en cualquier circunstancia a partir del llenado de formularios, encuestas o en los trámites ante alguna instancia, pública o privada. En estos casos la ley es clara con el aviso de privacidad como el instrumento idóneo para llevar a cabo la recolección de datos personales.

${ }^{18}$ Sánchez Abril, Patricia, et al. "Health Privacy in a Techno-Social World: A Cyber-Patient's Bill of Rights”, en Northwestern Journal of Technology and Intellectual Property, número 6, Verano, 2008, pp. 244-277.

${ }^{19}$ Maheshwari, Sapna, "That Game on Your Phone May Be Tracking What You're Watching on TV", en The New York Times, 28 de diciembre de 2017. Recuperado el 13 de septiembre de 2018, de https:/www.nytimes.com/2017/12/28/business/media/ alphonso-app-tracking.html

${ }^{20}$ Solove, Daniel J., "A Taxonomy of Privacy” en University of Pennsilvania Law Review, Volumen 154, Enero de 2006, Número 3, pp 477-560. 
Por lo que respecta al procesamiento de datos, también pueden identificarse una serie de características en las que se puede incurrir en responsabilidades. El uso, almacenamiento y manipulación de los datos personales entran en esta actividad. Dentro del procesamiento de datos se pueden distinguir momentos específicos como la incorporación, identificación, medidas de seguridad, usos secundarios y exclusiones.

Por su parte la difusión de datos personales es el quebrantamiento de la confidencialidad, es la exposición total de los datos que se saben fueron entregados con un fin específico y se han divulgado, sin consentimiento, por supuesto, de su titular. También se puede considerar como difusión cuando se comparten los datos personales con otras personas o entidades públicas o privadas. Al respecto, en el orden jurídico nacional hay una serie de responsabilidades civiles, administrativas y penales, por lo que puede trascender al ámbito del daño moral.

\section{LIBRE DESARROLLO DE LA PERSONALIDAD}

Consideramos que un tercer componente del derecho a la privacidad se encuentra en las disposiciones sobre el libre desarrollo de la personalidad. Se conoce bajo este concepto al derecho de una persona o personas a ser libres de tomar decisiones sin interferencia del poder público en materias fundamentales que les afecten en su vida, esto incluye el establecimiento de un plan de vida individual. Es importante destacar los elementos que revisten a este tipo de derechos, que sin duda están dispersos en el orden jurídico y que su definición ha reposado más en la interpretación de los tribunales que en normas de fuente legal. Aunque las materias que inciden en este derecho son variadas, hay un común denominador en las decisiones sobre la sexualidad, control natal, adicciones y un abundante número de formas en que el desarrollo de la personalidad puede asociarse.

Cabe destacar que este derecho está inextricablemente relacionado con la privacidad, a pesar de que existan argumentos en contra que lo 
vinculan más con la autonomía y la libertad de las personas. ${ }^{21}$ Sin embargo, tanto la libertad personal como la autonomía las consideramos dentro de una "zona de privacidad", como lo entienden otros teóricos al respecto. ${ }^{22}$ En la idea moderna de los contratos existe esta mínima interferencia al establecer en varias parte del derecho civil y mercantil las expresiones "voluntad de los contratantes", "voluntad del testador", como una especie de supremacía de la voluntad que solamente tendrá límites específicos en tanto sean contrarios al interés público. ${ }^{23}$ En estos casos, claramente se refiere a la autonomía y libertad contractuales. Las disposiciones que atañen al libre desarrollo de la personalidad tienen otra naturaleza, dado que inciden en cuestiones mas íntimas de las personas dentro de su plan de vida y facultad de decisión.

Normas que invadan el ejercicio individual por interés público sin duda están ampliamente justificadas, de ahí la misma base y fundamento del control social. El papel del derecho ante el libre desarrollo de la personalidad es complejo y tiene una gran cantidad de cuestionamientos. Las normas jurídicas pretenden guiar la conductas de las personas, en este sentido, esa conducción hasta dónde puede considerarse que no traspase la esfera de la individualidad, las decisiones personales en una persona no menor de edad, por supuesto, con toda la capacidad de ejercicio legal.

En el derecho angloamericano se ha pulido a partir de la doctrina y la jurisprudencia el concepto de interferencia decisional (decisional interference),

${ }^{21}$ Dado que el daño de una disposición invasiva en las decisiones es en contra de la autonomía y la libertad personal, no se trata de un componente de derecho a la privacidad. Tribe, Laurence H, American Constitutional Law, 2da edición, The Foundation Press, 1998, New York, Estados Unidos, pp 1352.

${ }^{22}$ Solove, Daniel J., "A Taxonomy of Privacy" en University of Pennsilvania Law Review, Volumen 154, Enero de 2006, Número 3, pp. 477-560.

${ }^{23}$ Al respecto el Código Civil Federal establece los límites a la voluntad humana.

Artículo 6o.- La voluntad de los particulares no puede eximir de la observancia de la ley, ni alterarla o modificarla. Sólo pueden renunciarse los derechos privados que no afecten directamente al interés público, cuando la renuncia no perjudique derechos de tercero. 
que da luz al concepto que abordamos en este apartado. ${ }^{24} \mathrm{Su}$ significado está centrado en los aspectos de la vida que son consideraros socialmente como los más íntimos. ${ }^{25}$ Este concepto comparte similitudes con la mínima injerencia porque en los dos casos se refiere a la invasión en la esfera personal en la que se supone no deba haber ninguna incursión sin el debido consentimiento o bien sin justificación legal que lo revista de válido. Sin embargo, el diferenciador es que la mínima injerencia se desarrolla en el contexto de las actividades de las personas, su familia, sus posesiones y el libre desarrollo de la personalidad es la intromisión en sus decisiones.

La larga doctrina sobre la privacidad creada por la academia y los tribunales estadounidenses desarrolló la idea de un derecho basado en la prohibición de interferir en las decisiones de vida de los demás. Se conoce como Derecho a no ser molestado (Right to be let alone ${ }^{26}$ y tuvo sus primeras interpretaciones a finales del siglo XIX.${ }^{27}$ De acuerdo con la jurisprudencia el Derecho a no ser molestado consiste en la facultad de todo individuo de poseer y controlar su propia persona, libre de toda restricción e interferencia de otros, a menos de que exista una incuestionable autoridad derivada de disposiciones jurídicas. ${ }^{28}$ De manera más contemporánea,

${ }^{24}$ Stark-Smith, Gesse et al., "Privacy in the Time of American War", en Aspray, William, Doty, Philip (editores), Privacy in America: Interdisciplinary Perspectives, The Scarecrow Press, 2011, pp 249.

${ }^{25}$ Solove, Daniel J., "A Taxonomy of Privacy" en University of Pennsilvania Law Review, Volumen 154, Enero de 2006, Número 3, pp. 477-560.

${ }^{26}$ A pesar de que la palabra alone significa en términos literales "estar solo", también tiene como acepción la idea de "molestia", cuyo término consideramos más adecuado. La expresión Leave me alone, más que “déjame solo”, significa, “déjame en paz”. Definición de alone en wrew.yourdictionary.com. Recuperado el 18 de septiembre de 2018 en http://www.yourdictionary.com/alone?direct_search_result=yes

${ }^{27}$ Warren, Samuel D., Brandeis, Louis D., "The Right to Privacy" en Harvard Law Review, Vol. 4, No. 5. (Dec. 15, 1890), pp. 193-220.

${ }^{28} \mathrm{El}$ caso comentado es Union Pacific Railway Co. v. Botsford, 141 U.S. 250 (1891), derivado de una examinación medica forzosa que le querían hacer sin su consentimiento a la señora Botsford desató este comentario por parte del juez Gray. No right is held more sacred or is more carefully guarded by the common law than the right of every individual to the possession and control of his own person, free from all restraint or interference of others unless by clear and unquestionable authority of law. 
en otro juicio se determinó que la posesión de pornografía no podía ser penalizada por las instituciones públicas, en virtud de que constituiría una interferencia en la vida privada de las personas. ${ }^{29}$ Un tercer juicio -emblemático en la jurisprudencia angloamericana- es Lawrence v. Texas, en el que se alegó la prohibición legal texana de tener relaciones consensuadas sodomitas entre hombres, a lo que la Corte Suprema concluyó:

La libertad protege a las personas de intrusiones injustificadas del gobierno en su domicilio u otros lugares privados. En nuestra tradición el Estado no está omnipresente en todos los hogares. Hay otras esferas de nuestras vidas y existencia fuera de nuestras casas, en donde el Estado no debe tener presencia dominante. La libertad se extiende más allá de los límites espaciales. La libertad presume la autonomía personal que incluye la libertad de pensamiento, creencia, expresión y determinadas conductas íntimas. Este caso envuelve la libertad de las personas tanto de manera espacial como en dimensiones más trascendentes. ${ }^{30}$

Por su parte, en México, se ha iniciado una discusión que incluye el libre desarrollo de la personalidad a partir de la impugnación de varias normas de la Ley General de Salud que prohíben actos como la siembra, cultivo, cosecha, preparación, adquisición, posesión, comercio, transporte, prescripción médica, suministro, empleo, uso y consumo de estupefacientes. $\mathrm{Al}$ respecto, el artículo 237 de la Ley hace mención expresa de que todas las actividades mencionadas estarán prohibidas cuando se trate de varias sustancias entre ellas la mariguana (cannabis sativa, índica y americana). ${ }^{31}$ Cabe destacar que para efectos de la Ley, el Tetrahidrocannabinol, sustancia activa de la marigua-

${ }^{29}$ Esto se determinó en el caso Stanley v. Georgia, 394 U.S. 557 (1969). Recuperado el 18 de septiembre de 2018 en https://supreme.justia.com/cases/federal/us/394/557/

${ }^{30}$ Véase Lawrence v. Texas, 539 U.S. 558 (2003). Recuperado el 18 de septiembre de 2018 en https://supreme.justia.com/cases/federal/us/539/558/

Liberty protects the person from unwarranted government intrusions into a dwelling or other private places. In our tradition the State is not omnipresent in the home. And there are other spheres of our lives and existence, outside the home, where the State should not be a dominant presence. Freedom extends beyond spatial bounds. Liberty presumes an autonomy of self that includes freedom of thought, belief, expression, and certain intimate conduct. The instant case involves liberty of the person both in its spatial and more transcendent dimensions.

${ }^{31}$ Se trata de los artículo 235, 237, 245, fracción I, 247 en su último párrafo y 248 de la Ley General de Salud 
na, está considerado de bajo valor terapéutico, pero como un importante problema de salud pública (245, fracción I). Cabe destacar que no hay en el cuerpo de la Ley una prohibición absoluta a todos los actos señalados, esto es que podrán llevar a cabo siempre que sus fines sean médicos y científicos y con autorización de la Secretaría de Salud (247, último párrafo).

$\mathrm{Al}$ respecto se han llevado a cabo procedimientos por vía del juicio de amparo para declarar la inconstitucionalidad de los artículos de la Ley General de Salud, dado que establecen una prohibición que lesiona entre otros derechos el libre desarrollo de la personalidad. ${ }^{32}$ La idea está centrada en que las personas que quieran consumir mariguana, porque así lo han decidido y lo consideran su plan de vida, no lo pueden hacer con esta batería de disposiciones jurídicas, que sin duda son prohibicionistas. Cabe señalar que las prohibiciones sobre decisiones personales son normalmente incompatibles con el libre desarrollo de la personalidad y en este caso pareciera que así es. Sin embargo, hay que tener presente que la mariguana es un psicotrópico y representa un grave problema de salud pública.

Los juicios de amparo han prosperado, se han declarado en tres sentencias la inconstitucionalidad de los artículo de la Ley General de Salud y se ha ordenado a la autoridad reguladora (SS-COFEPRIS) que "emita autorizaciones para realizar las actividades relacionadas con el autoconsumo con fines lúdicos o recreativos - sembrar, cultivar, cosechar, preparar, poseer y transportar- del estupefaciente “cannabis" (sativa, índica y americana o mariguana, su resina, preparados y semillas) y del psicotrópico "THC" (tetrahidrocannabinol)..."33

\footnotetext{
${ }^{32}$ A la fecha existen 3 sentencias de Amparo que han declarado inconstitucionales los artículos de la Ley General de Salud.

Amparo 237/14, recuperado el 18 de septiembre de 2018 en https://es.scribd.com/ document/288517633/Resumen-Ejecutivo-Marihuana\#fullscreen\&from_embed Amparo 1115/2017, recuperado el 18 de septiembre de 2018 en https://www.scjn.gob. mx/sites/default/files/listas/documento_dos/2018-03/AR-1115-17-180316.pdf

Amparo 623/2017, recuperado el 18 de septiembre de 2018 en https:/www.scjn.gob. $\mathrm{mx} / \mathrm{sites} /$ default/files/listas/documento_dos/2018-(04/AR-623-2017-180430.pdf

${ }^{33}$ Séptimo Resolutivo del Amparo en revisión 1115/2017.
} 
Desde nuestro punto de vista estas sentencias están incompletas y erróneas por los siguientes motivos. Si bien consideramos que la argumentación sobre la interferencia decisoria de la Ley General de Salud es correcta, también debemos anotar que el poder público, en este caso el Gobierno, debe tener una estrategia persuasiva, que genere conciencia a la ciudadanía sobre los efectos de la mariguana en el sistema nervioso, lo cual no existe, o al menos lo debió ordenar la Suprema Corte. Esto se refiere al papel que debe tener el poder público enfrente del libre desarrollo de la personalidad, el cual debe ser persuasivo y no prohibitivo. En estos casos las prohibiciones se están eliminando, pero no se está garantizando el nivel de responsabilidades del Gobierno en persuadir a la población de que no consuman mariguana.

\section{CONSIDERACIONES FINALES}

Existen un gran número de disposiciones jurídicas que atañen o inciden directa e inmediatamente a la privacidad de las personas, a todas esas normas las acuñamos como el derecho objetivo a la privacidad. De ese enorme conjunto, las que declaran alguna facultad o una prerrogativa a las personas las consideramos como derecho subjetivo a la privacidad. Por otro lado, consideramos que el derecho a la privacidad lo podemos circunscribir a tres componentes esenciales. Esto es, a las normas que determinan la mínima injerencia del poder público en su vida, familia, posesiones; las que tutelan los datos personales; y las que interfieren en la persona, pero desde el punto de vista de sus decisiones y su plan de vida, esto es las que corresponden al libre desarrollo de la personalidad.

De esta manera, creemos concluyente que en el contexto de esta aproximación metodológica se pueden encasillar todas las disposiciones jurídicas relacionadas con la privacidad de las personas.

Creemos que la aproximación metodológica que presentamos ofrece una ventana de oportunidades para poder llevar a cabo alguna evaluaciones sobre el derecho a la privacidad, que s traducen en parámetros que deben considerarse en la generación de políticas públicas. En principio, por lo que respecta a la mínima injerencia, consideramos que siempre deberá configurarse bajo una exhaustiva argumentación y en todo caso 
la convalidación judicial es altamente necesaria; por lo que respecta a la protección de datos personales, los derechos ARCO, deben estar desregulados al máximo para que los titulares tengan la oportunidad de ejercitarlos de forma expedita; de igual manera, cuando se pretende generar alguna política pública, se deberá tomar en cuenta si es compatible con el libre desarrollo de la personalidad de las personas, en este sentido, también consideramos que el papel del poder público enfrente de las decisiones de las personas debe ser en todo momento persuasivo y no prohibitivo.

VI. FUENTES

\section{DOCTRINA}

ABBAgNANO, Nicola, Diccionario de Filosofia, México, Fondo de Cultura Económica, 1963, pp. 738-747.

BLOUSTEIN, Edward, "Privacy as an Aspect of Human Dignity", en New York University Law Review, NYU, Volumen 39, 1964

DWORKIN, Ronald, "Hard Cases", en Harvard Law Review, Vol. 88, No. 6 (Apr., 1975).

FERRAJOLI, Luigi, Derechos y Garantías. La ley del mas débil, Editorial Trotta, 2002.

MAHESHWARI, Sapna, "That Game on Your Phone May Be Tracking What You're Watching on TV", en The New York Times, 28 de diciembre de 2017. Recuperado el 13 de septiembre de 2018, de https://www.nytimes. com/2017/12/28/business/media/alphonso-app-tracking.html

O CAllaghan, Patrick, Refining Privicy in Tort Law, Reino Unido, Ed. Springer, 2013, 184 pp.

PROSSER, William M, Privacy, California Law Review, Volumen 48, Número 3, Agosto de 1960, 383-423

SÁNCHEZ, Abril Patricia, et al. "Health Privacy in a Techno-Social World: A Cyber-Patient's Bill of Rights”, en Northwestern Fournal of Technology and Intellectual Property, número 6, Verano, 2008, pp. 244-277. 
SOLOVE, Daniel J., "A Taxonomy of Privacy” en University of Pennsilvania Law Review, Volumen 154, Enero de 2006, Número 3, pp 477-560.

STARK-SMITH, Gesse et al., "Privacy in the Time of American War", en Aspray, William, Doty, Philip (editores), Privacy in America: Interdisciplinary Perspectives, The Scarecrow Press, 2011, pp 249

TRIBE, Laurence H, American Constitutional Law , 2da edición, The Foundation Press, 1998, New York, Estados Unidos, pp 1352.

WARREN, Samuel D., Brandeis, Louis D., "The Right to Privacy" en Harvard Law Review, Vol. 4, No. 5. (Dec. 15, 1890), pp. 193-220.

\section{ORDEN JURÍDICO}

Amparo 237/14, recuperado el 18 de septiembre de 2018 en https:/es.scribd.com/document/288517633/Resumen-Ejecutivo-Marihuana\#fullscreen\&from_embed

Amparo 1115/2017, recuperado el 18 de septiembre de 2018 en https://www.scjn.gob.mx/ sites/default/files/listas/documento_dos/2018-03/AR-1115-17-180316.pdf

Amparo 623/2017, recuperado el 18 de septiembre de 2018 en https://www.scjn.gob.mx/ sites/default/files/listas/documento_dos/2018-04/AR-623-2017-180430.pdf

Caso Lawrence v. Texas, 539 U.S. 558 (2003). Recuperado el 18 de septiembre de 2018 en https://supreme.justia.com/cases/federal/us/539/558/

Caso Stanley v. Georgia, 394 U.S. 557 (1969). Recuperado el 18 de septiembre de 2018 en https://supreme.justia.com/cases/federal/us/394/557/

Caso Union Pacific Railway Co. v. Botsford, 141 U.S. 250 (1891)

\section{CÓDIGO CIVIL FEDERAL}

Decreto publicado en el Diario Oficial de la Federación el 17 de junio de 2016, se puede consultar en la siguiente cibergrafía http://www.dof.gob.mx/nota_detalle. php? $\operatorname{codigo}=5441763 \&$ fecha $=17 / 06 / 2016$ 
Ley Federal de Protección de Datos Personales en Posesión de Particulares

Ley General de Salud

Ley General de Protección de Datos Personales en Posesión de Sujetos Obligados

Sentencia de las acciones de inconstitucionalidad 10/2014 y 11/2014 acumulada promovidas por la Comisión Nacional de los Derechos Humanos y el Instituto Federal de Acceso a la Información Pública Gubernamental ante la Suprema Corte de Justicia de la Nación. Recuperado el 5 de septiembre de 2018. Se pueden consultar en la siguiente cibergrafía http://www.cndh.org. mx/sites/all/doc/Acciones/Acc_Inc_2014_10_Demanda.pdf 
